\title{
Novel UHF RFID Near-Field Reader Antenna with Uniform Vertical Electric Field Distribution
}

\author{
Yanbin Chen, ${ }^{1}$ Xiaojuan Ren, ${ }^{2}$ Jimin Zhao, ${ }^{1}$ Xin Chen, ${ }^{1}$ Yuan Yao $\mathbb{D}^{2},{ }^{2}$ Junsheng Yu $\mathbb{D},{ }^{2}$ \\ and Xiaodong Chen ${ }^{3}$ \\ ${ }^{1}$ Space Star Technology CO., LTD, Beijing, China \\ ${ }^{2}$ School of Electronic Engineering, Beijing University of Posts and Telecommunications, Beijing, China \\ ${ }^{3}$ School of Electronic Engineering and Computer Science, Queen Mary University of London, London, UK
}

Correspondence should be addressed to Yuan Yao; yaoy@bupt.edu.cn

Received 14 May 2020; Revised 24 July 2020; Accepted 3 August 2020; Published 24 August 2020

Academic Editor: Mauro Parise

Copyright (C) 2020 Yanbin Chen et al. This is an open access article distributed under the Creative Commons Attribution License, which permits unrestricted use, distribution, and reproduction in any medium, provided the original work is properly cited.

This paper presents two novel UHF RFID near-field reader antennas with uniform vertical electric field distribution. The two antennas have the following common characteristics. First, the radiating parts of the two antennas are simulated and fabricated by the microstrip lines and work using the leakage wave principle of microstrip lines. Second, the end of microstrip lines match the load to form a traveling wave mode of operation, so the two antennas have broadband characteristics. Third, both antennas are fed in a coaxial manner at the center of the antenna. The simulation and measurement results can show that the proposed threebranch antenna and four-branch antenna achieve good impedance matching in the range of $883-960 \mathrm{MHz}$ and $870-960 \mathrm{MHz}$, respectively, and achieve uniform distribution of the vertical electric field component in a certain area. The reading areas of the three-branch antenna and the four-branch antenna are $70 \mathrm{~mm} \times 70 \mathrm{~mm} \times 90 \mathrm{~mm}$ and $100 \mathrm{~mm} \times 100 \mathrm{~mm} \times 120 \mathrm{~mm}$ (length $\times$ width $\times$ height), respectively. Due to the introduction of the ground plate, the antenna gain is low, which meets the design requirements of near-field antennas.

\section{Introduction}

Radio frequency identification (RFID) is a wireless noncontact communication technology that uses radio frequency signals to identify specific targets and complete data exchange. Because of its excellent characteristics such as no contact, reliable communication, automatic identification of moving targets, and fast reading and writing, RFID technology has received the attention and rapid development since its inception. RFID has become an indispensable part of our lives in today's era [1] and is widely used in various fields, such as logistics systems, access control management, electronic wallets, identity recognition, warehouse management, and positioning [2,3]. Traditional RFID technology has been relatively mature. As the Internet of Things gradually enters people's lives, RFID near-field application scenarios are increasing day by day, and near-field RFID has attracted much attention [4]. One of the most important factors affecting the performance of an RFID system is the reader antenna, which determines its near-field or far-field application.

In recent years, domestic and foreign experts and scholars have invested in the research boom of near-field RFID antennas [5]. The design difficulty of the near-field reader antenna is to ensure that the electromagnetic field can be uniformly distributed in the reading area and attenuate rapidly outside the reading area. According to different coupling mechanisms, RFID systems can be divided into two parts: magnetic field coupling and capacitive coupling. The magnetic field coupling system can adapt to harsh environments, but the reading distance is short. The magnetic field coupling antenna generally adopts a loop structure, including large loop antennas and area expandable antennas. In order to achieve uniform distribution of the magnetic field, the large loop antenna needs to solve the problem of reverse current on the loop. The commonly used design 
methods include loading capacitor [6, 7], using segment line [8], adding phase shifter [9], and zero-phase-shift loop antenna $[10,11]$. Although large loop antennas can achieve uniform magnetic field distribution, they generally have high gain characteristics. Another type of antenna with low gain characteristics can achieve the expandability of the reading area [12]. The capacitive coupling system has poor anti-interference performance, but its reading distance is relatively long, which can meet more application requirements. This type of antenna needs to pay attention to the polarization direction of the reader antenna and the tag antenna. In order to read linearly polarized tags arbitrarily placed in the reading area, it is required that the electric field generated by the reader antenna be uniform and controllable in three-dimensional space. The circularly polarized antenna $[13,14]$ can radiate and receive circularly polarized waves. The multipolarized near-field reader antenna [15] can provide a strong and uniform electric field distribution in the area to be read and has a low far-field gain. However, the reading area of this antenna is fixed and cannot be extended to different scenarios. A multipolarized reader antenna [16] was then proposed to support the expansion of the reading area.

After all, the near-field field distribution is complicated. In order to achieve $100 \%$ reading of tags placed randomly in the reading area, the capacitively coupling RFID reader antenna needs to consider the uniformity of the electric field threedimensional component. However, the current research mainly focuses on the uniformity of the total electric field strength. In this paper, two novel capacitively coupling RFID reader antennas are proposed. The vertical electric field components excited by two antennas are uniformly distributed in the reading area. And two antennas can achieve 100\% reading of tags placed vertically in the reading area. Both antennas are traveling wave antennas with good impedance matching characteristics. At present, few scholars discuss and design the vertical electric field component. This paper considers the uniform distribution of this component separately, so it can provide an important reference value for the research of near-field reader antenna with uniform electric field distribution in the three-dimensional direction.

\section{Antenna Design}

2.1. Configuration. Figures 1 and 2 are configurations of the two proposed antennas. It can be seen from the two figures that the radiating parts of the two antennas are both centersymmetric microstrip line structures. The microstrip line end of each branch is connected to a $50 \mathrm{ohm}$ resistor to form an antenna structure that carries traveling wave current. Both antennas use FR4 with a dielectric constant of 4.4 as the dielectric substrate with a thickness of $h$, and the size of the ground plate is the same as the dielectric substrate. The parameters of the three-branch antenna and the four-branch antenna after parameter scanning optimization are shown in Tables 1 and 2, respectively.

2.2. Working Principle. The radiating parts of the two antennas are center-symmetrical, and the coaxial feed is used at the center of the two antennas. The current between the inner and outer conductors of the coaxial structure generates a vertical electric field. Current leaks along the microstrip while radiating. Leakage waves include surface waves in the horizontal direction and space waves in the vertical direction. We use the vertical space waves leaked by the microstrip lines to achieve uniform vertical electric field distribution of the two antennas.

Figure 3 shows the current distribution on the two antennas. It can be seen that this type of structure makes the current have an antiphase distribution characteristic between symmetrical branches. This characteristic, on the one hand, causes the electric field to cancel each other in the farfield area and quickly decay. On the other hand, the lateral leakage waves are cancelled out, weakening their influence on the longitudinal electric field distribution. The current produces longitudinal space wave leakage along the symmetrical branches and achieves a uniform distribution of the electric field component perpendicular to the antenna surface.

\section{Results and Discussion}

To fully evaluate the working performance of the two antennas, they were simulated and measured separately. In this part, we mainly focused on the reflection coefficient, the distribution of the vertical electric field component, and the tag $100 \%$ reading area. In the analysis process, we assume that two antennas are placed in the XOY plane, where Ez represents the vertical electric field component.

3.1. Reflection Coefficient. Figures 4 and 5 show the measured and simulated reflection coefficients of the threebranch antenna and the four-branch antenna, respectively. It can be seen that the two proposed antennas are well matched (i.e., $\mathrm{S} 11<-10 \mathrm{~dB}$ ) in the range of $883-960 \mathrm{MHz}$ and $870-960 \mathrm{MHz}$, respectively. The measured S11 resonance point is slightly offset from the simulation results, and there are some gaps in size. Considering that it may be caused by insufficient machining accuracy and instability of the substrate, it can be ignored.

3.2. Far-Field Gain. Different from the far-field RFID antenna, the near-field RFID reader antenna is required to have low gain characteristics, so as to avoid misreading of tags outside the reading area and achieve a controllable reading range. Figure 6 shows the simulated gains of the two antennas versus frequency. It can be seen from the figure that the far-field gains of the two antennas are both low, and the electromagnetic wave propagation distance is very short, which can meet the needs of near-field applications.

3.3. Vertical Electric Field Distribution. Figures 7 and 8 show the simulated $\mathrm{Ez}$ distribution of two antennas at different heights. It can be seen from the two figures that the Ez distribution of the two antennas is uniform and controllable in a certain area. The Ez distribution of the two 


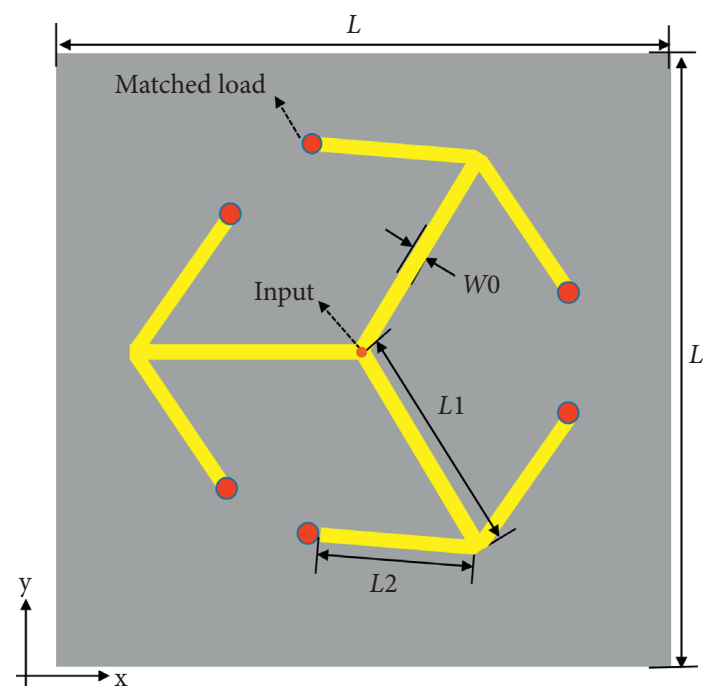

(a)

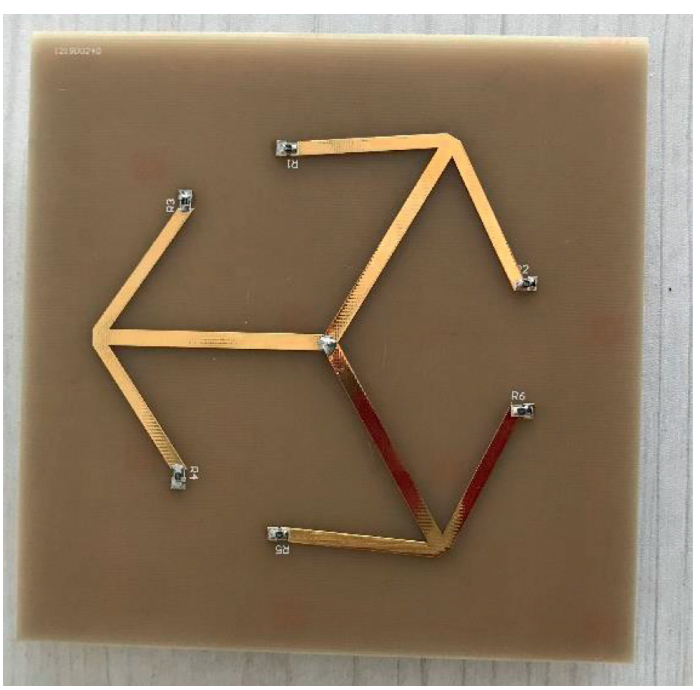

(b)

FIgURe 1: Configuration of the three-branch antenna. (a) Schematic diagram of structure. (b) Physical processing diagram.

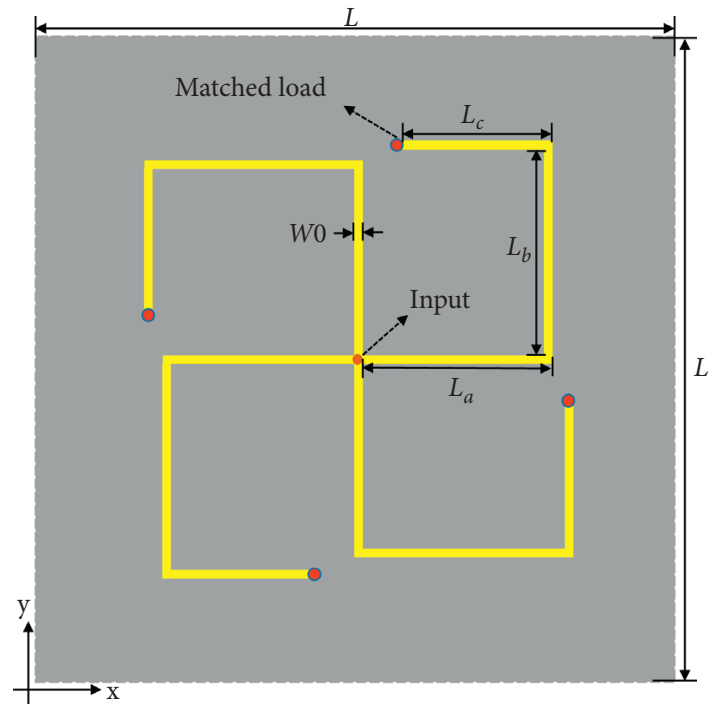

(a)

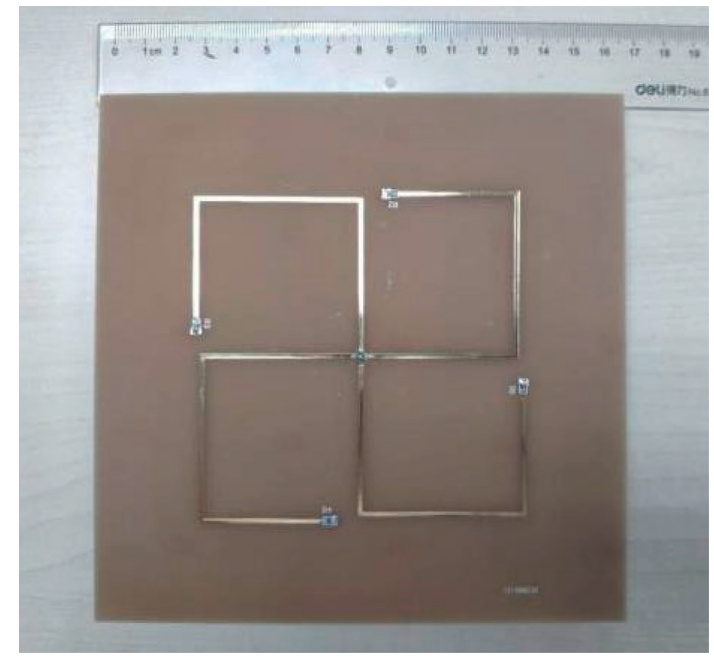

(b)

FIGURE 2: Configuration of the four-branch antenna. (a) Schematic diagram of structure. (b) Physical processing diagram.

TABLE 1: Optimized three-branch antenna parameters (unit: $\mathrm{mm}$ ).

\begin{tabular}{lccccc}
\hline Parameter & L & L1 & L2 & W0 & \\
\hline Value & 134.5 & 51.75 & 38.2 & 3.5 & 2 \\
\hline
\end{tabular}

TABLE 2: Optimized four-branch antenna parameters (unit: $\mathrm{mm}$ ).

\begin{tabular}{lcccccc}
\hline Parameter & L & La & Lb & Lc & W0 & \\
\hline Value & 165 & 49.5 & 49.5 & 38.5 & 1.3 & 2 \\
\hline
\end{tabular}




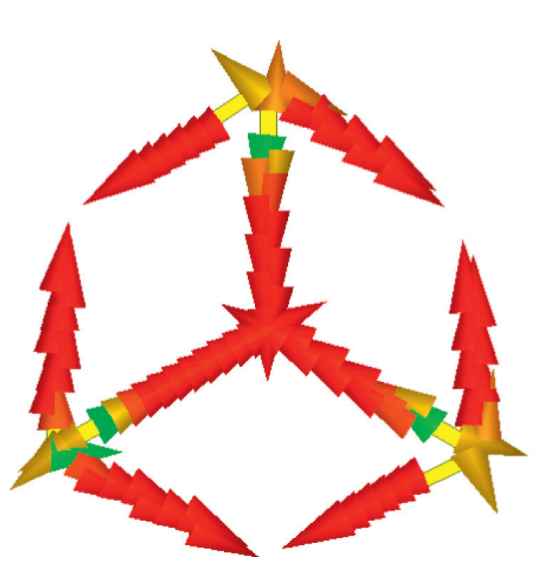

(a)

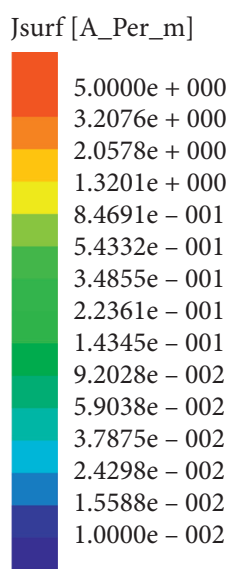

Figure 3: Current distribution. (a) Three-branch antenna. (b) Four-branch antenna.

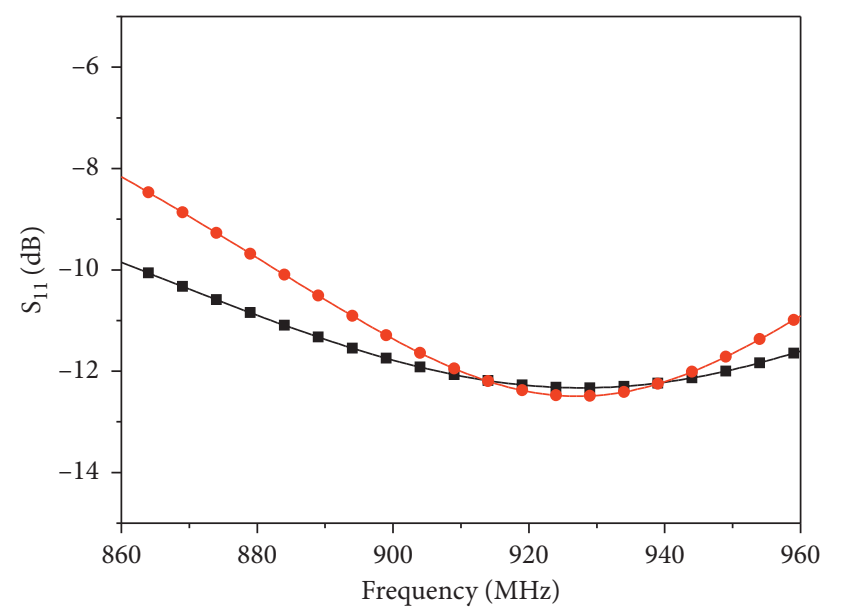

$\rightarrow$ Measured

$\rightarrow$ Simulated

FIGURE 4: Simulated and measured reflection coefficients of the three-branch antenna.

antennas has the same characteristics. At the same height from the antenna surface, the electric field is the strongest above the center of the antenna; as the distance from the center increases, the vertical electric field component becomes weaker. Both the electric field strength and the coverage area decrease with the increase of the distance from the antenna surface, and there is no zero point existing in the antenna reading area. Because the longitudinal space wave of the microstrip line leaks little, the intensity of the electric field component in the vertical direction of the antenna is weak, and the vertical reading distance is short.

3.4. Reading Area. We used the proposed two antennas, Impinj Speedway R420 reader, application software, Alien A9662 electrical tag, RF cable, and foam board to build an

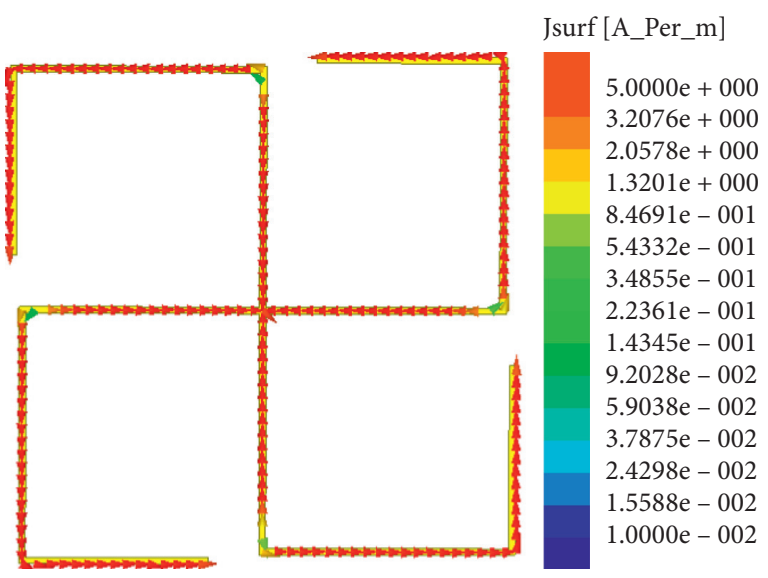

(b)

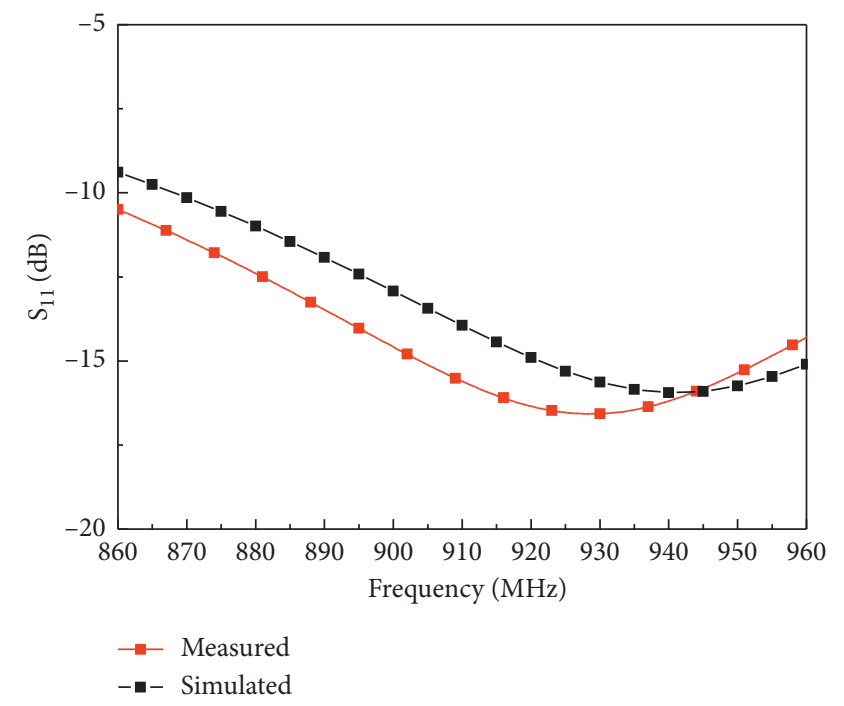

FIGURE 5: Simulated and measured reflection coefficients of the four-branch antenna.

RFID near-field measurement system in a relatively large space. RF cable was used to connect the reader and antenna, and TCP/IP connections were used to communicate between application software and the reader. The size of the tag used by the measurement system was $70 \mathrm{~mm} \times 17 \mathrm{~mm}$. The foam board was divided into grids, and the dimensions of each grid was $35 \mathrm{~mm} \times 35 \mathrm{~mm}$ for three-branch antenna, and $33.3 \mathrm{~mm} \times 33.3 \mathrm{~mm}$ for four-branch antenna. To measure the reading performance of the two antennas on vertically placed tags, we set up two measurement systems. Figure 9 shows the measurement system of the four-branch antenna; the measurement setup of a three-branch antenna was similar to that of a four-branch antenna except for the number of tags. During the measurement, the foam board was moved horizontally in the vertical direction, and the reading conditions of the tags were sequentially recorded at different heights from antenna. Repeat the measurement 


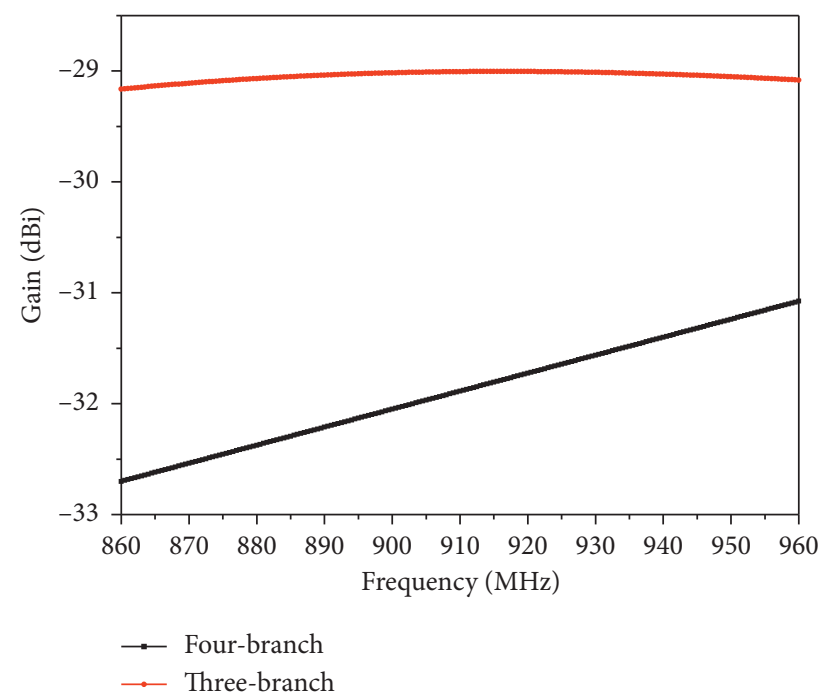

FiguRE 6: Simulated far-field gains of three-branch and four-branch antennas.

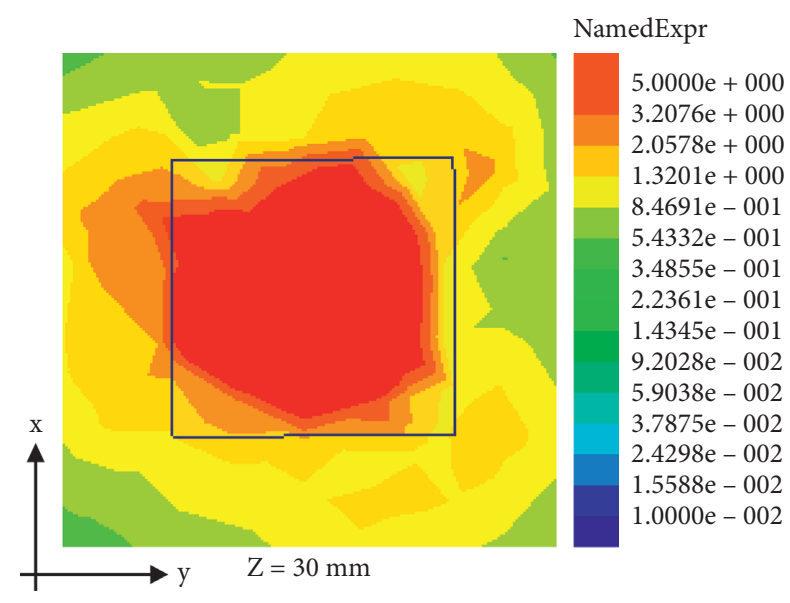

(a)

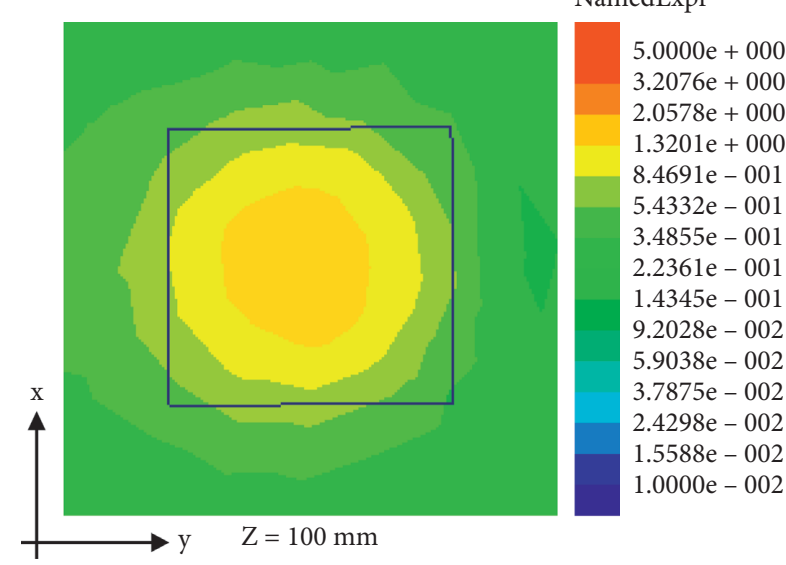

(c)

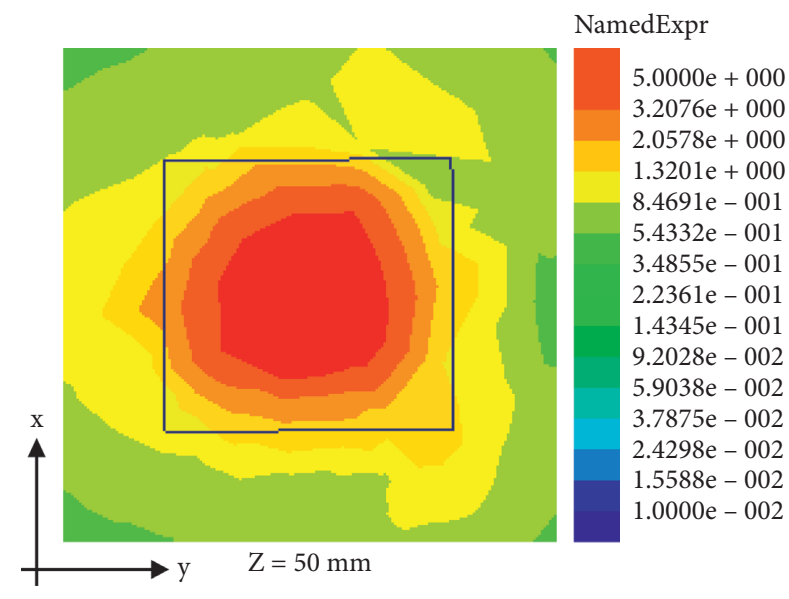

(b)

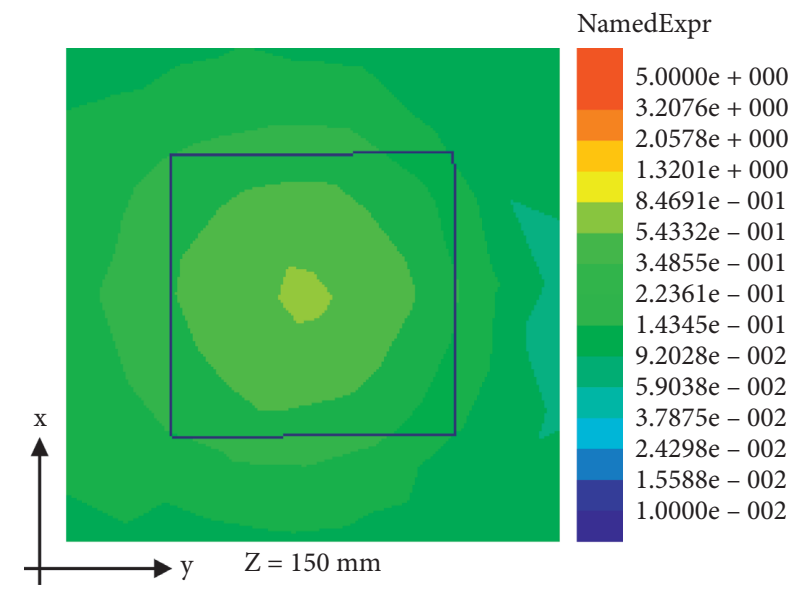

(d)

Figure 7: Simulated Ez distributions of the three-branch antenna at (a) $Z=30 \mathrm{~mm}$, (b) $Z=50 \mathrm{~mm}$, (c) $Z=100 \mathrm{~mm}$, and (d) $Z=150 \mathrm{~mm}$. 


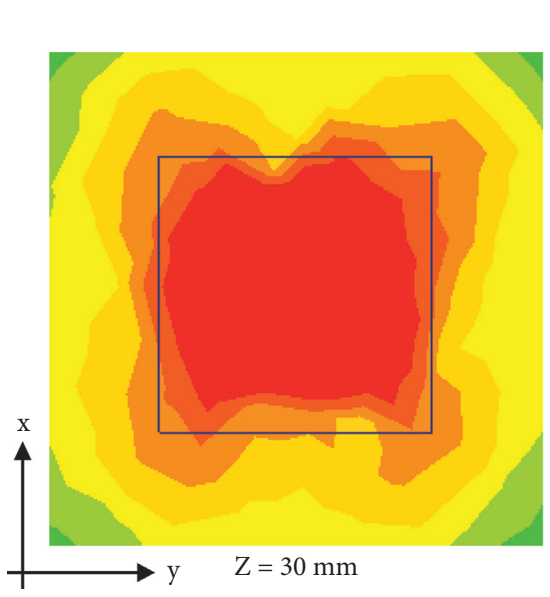

(a)

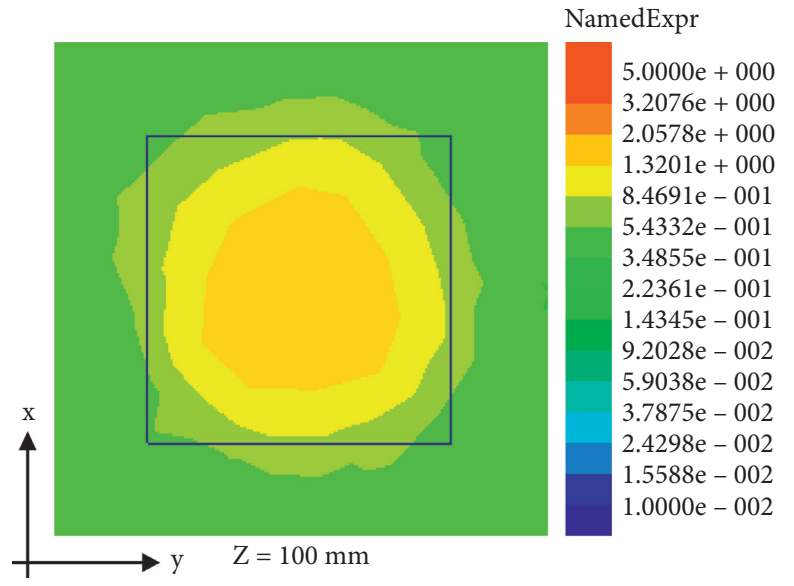

(c)
NamedExpr

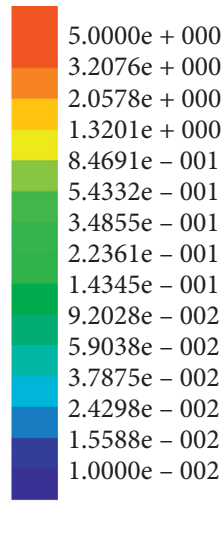

NamedExpr

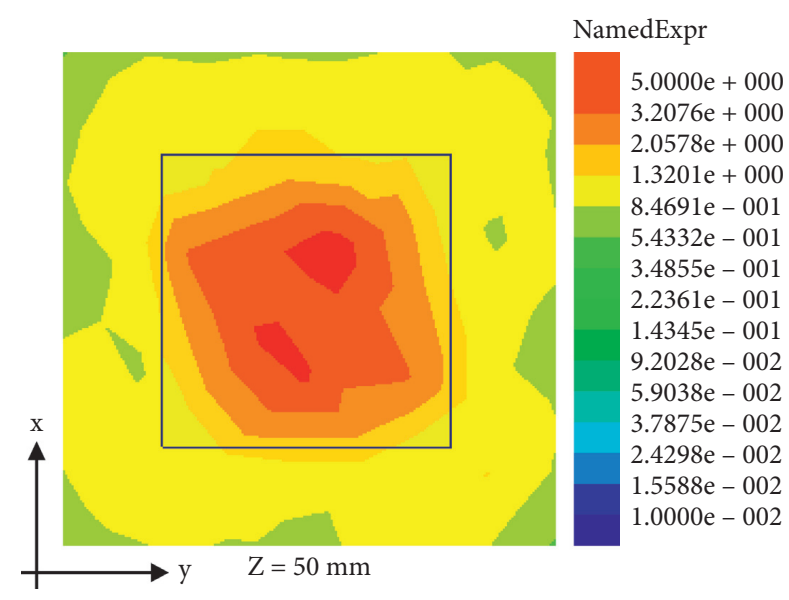

(b)

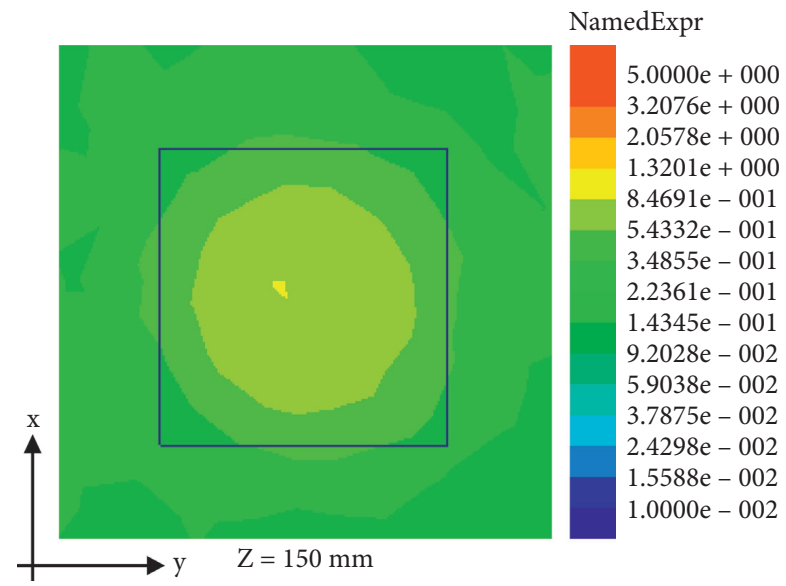

(d)

Figure 8: Simulated Ez distributions of the four-branch antenna at (a) $Z=30 \mathrm{~mm}$, (b) $Z=50 \mathrm{~mm}$, (c) $Z=100 \mathrm{~mm}$, and (d) $Z=150 \mathrm{~mm}$.

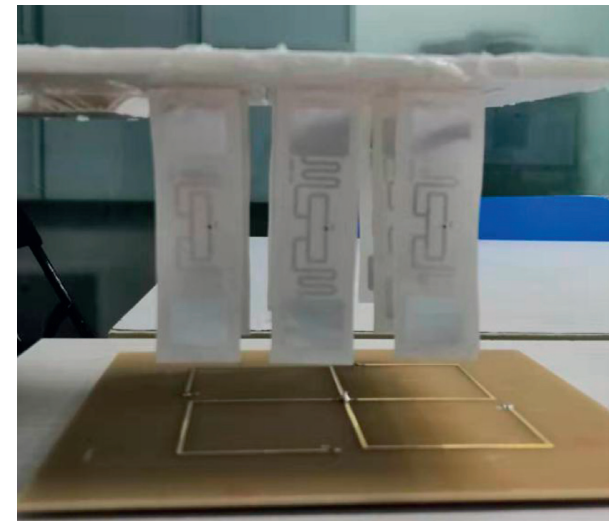

FIgURE 9: Four-branch antenna measurement setup.

several times to improve the measurement accuracy and plot the readings.

Figures 10 and 11 show the measurement results of reading area of the three-branch antenna and the fourbranch antenna, respectively. Green means that the tag in this area can be activated, and red means that the tag in this area cannot be activated. It can be seen that tags placed

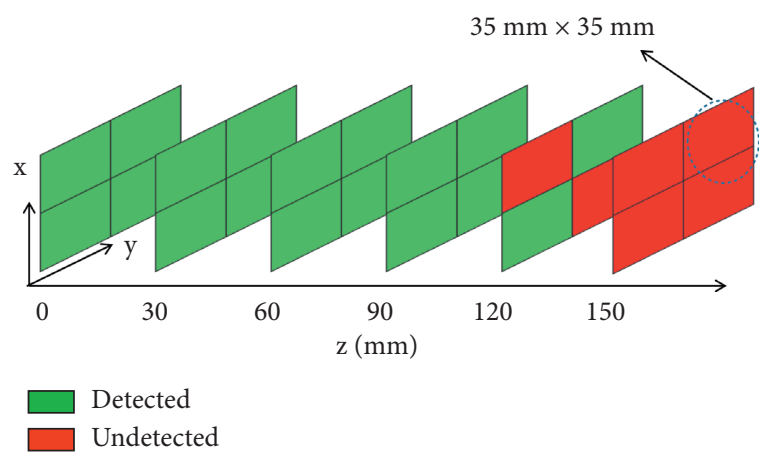

Figure 10: Three-branch antenna measurement results.

perpendicular to the antenna can be activated $100 \%$ within the area of $70 \mathrm{~mm} \times 70 \mathrm{~mm} \times 90 \mathrm{~mm}$ for three-branch antenna and $100 \mathrm{~mm} \times 100 \mathrm{~mm} \times 120 \mathrm{~mm}$ for four-branch antenna.

3.5. Parameter Analysis. The thickness and the dielectric constant of the substrate are the key parameters affecting the space wave leakage of the microstrip lines. These two 


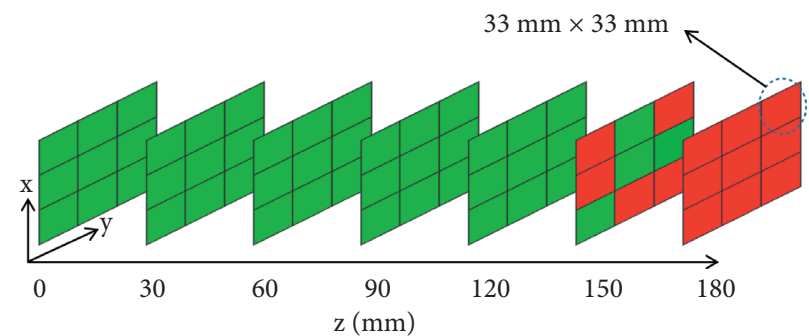

Detected

Undetected

FiguRE 11: Four-branch antenna measurement results.

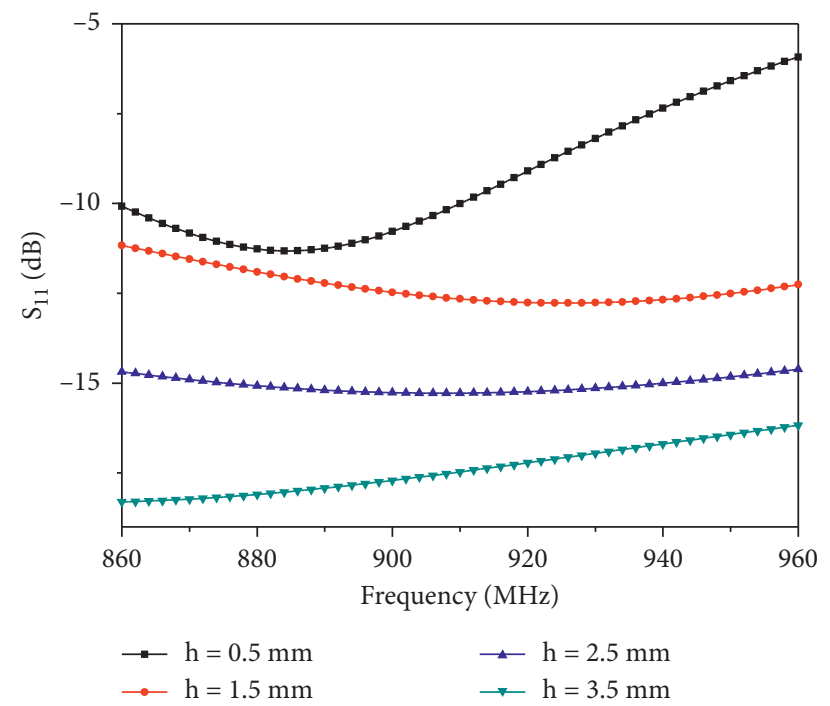

FIGURE 12: Simulated reflection coefficients of the three-branch antenna with different substrate thicknesses.

parameters were simulated, discussed, and analyzed. We took the three-branch antenna as an example for analysis.

3.6. Substrate Thickness. In order to analyze the influence of the substrate thickness on the antenna performance, we simulated the reflection coefficient and vertical electric field distribution when the substrate thickness of the three-branch antenna is $0.5 \mathrm{~mm}, 1.5 \mathrm{~mm}, 2.5 \mathrm{~mm}$, and $3.5 \mathrm{~mm}$ while keeping other parameters in Table 1 unchanged.

Figure 12 shows the simulated reflection coefficients of three-branch antennas with different substrate thicknesses. It can be seen from the figure that changing the thickness of the substrate has a great influence on the antenna reflection coefficient. In the simulated $860-960 \mathrm{MHz}$ range, except for the curve when $\mathrm{h}$ is $0.5 \mathrm{~mm}$, the remaining curves are all below $-10 \mathrm{~dB}$.

Figures 13-16 are the simulated Ez distributions of the three-branch antenna at different heights with different dielectric thicknesses. They are obtained on the same scale. Comparing the above figures, it can be seen that, within a certain range, the thicker the substrate is, the more the microstrip line space wave leaks and the stronger the vertical electric field radiated by the antenna at this time is.

3.7. Dielectric Constant. In order to analyze the influence of dielectric constant on the antenna performance, we simulated the reflection coefficient and vertical electric field distribution when the dielectric constant of the three-branch antenna is 1,3 , and 5 while keeping other parameters in Table 1 unchanged.

Figure 17 shows the simulated reflection coefficient of the three-branch antenna with different dielectric constants, where $r$ represents the dielectric constant. It can be seen from the figure that the dielectric constant has a significant effect on the antenna reflection coefficient. In the simulated $860-960 \mathrm{MHz}$, all $\mathrm{S}_{11}$ are less than $-10 \mathrm{~dB}$, which can meet the needs of ultrahigh-frequency band applications.

Figures 18-20 are the simulated Ez distributions of three-branch antenna at different heights with different dielectric constants. They are obtained on the same scale. Comparing the above figures, it can be seen that, within a certain range, the greater the dielectric constant, the less the space wave leakage of the microstrip line and the weaker the vertical electric field radiated by the antenna. 


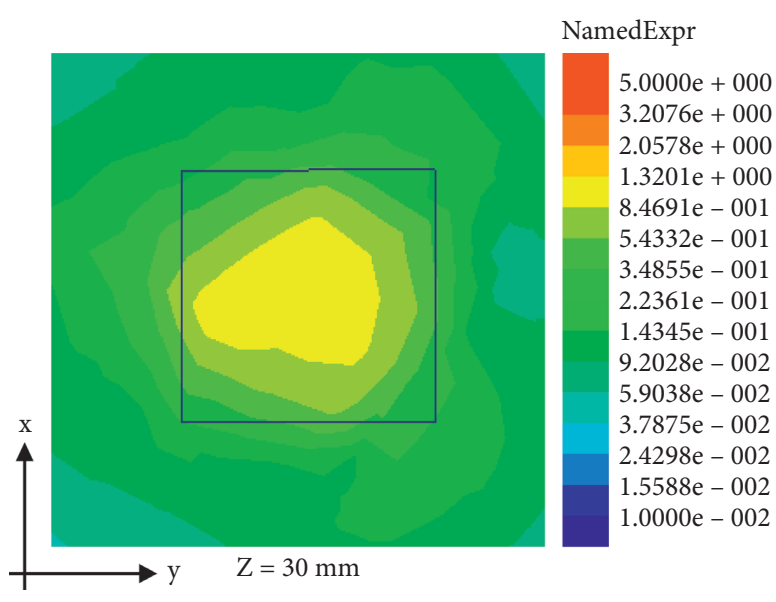

(a)

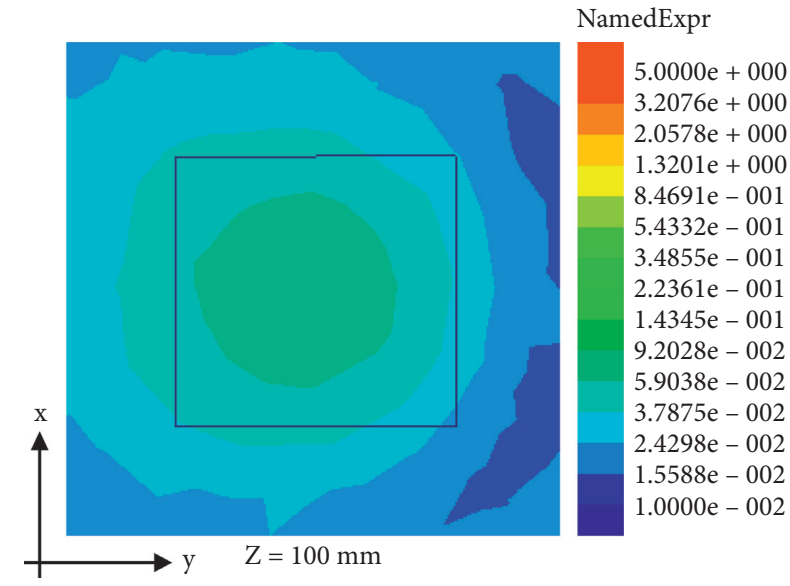

(c)

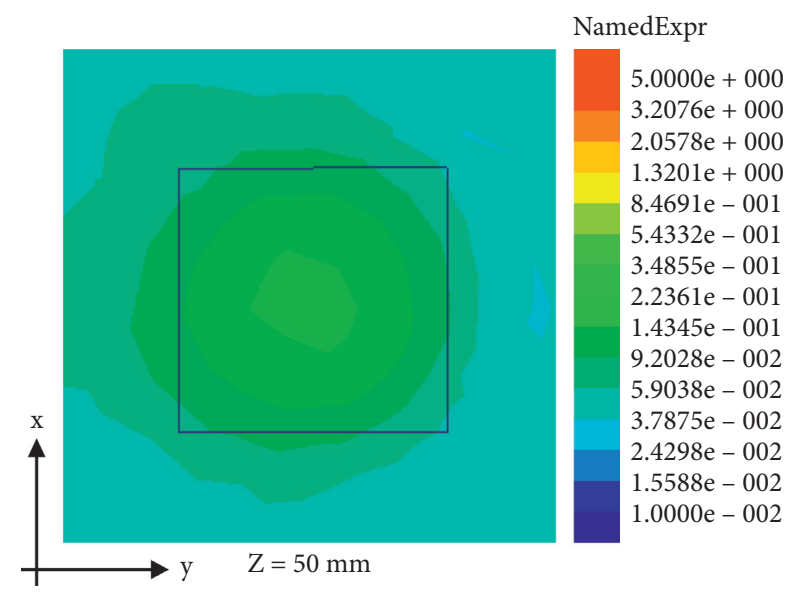

(b)

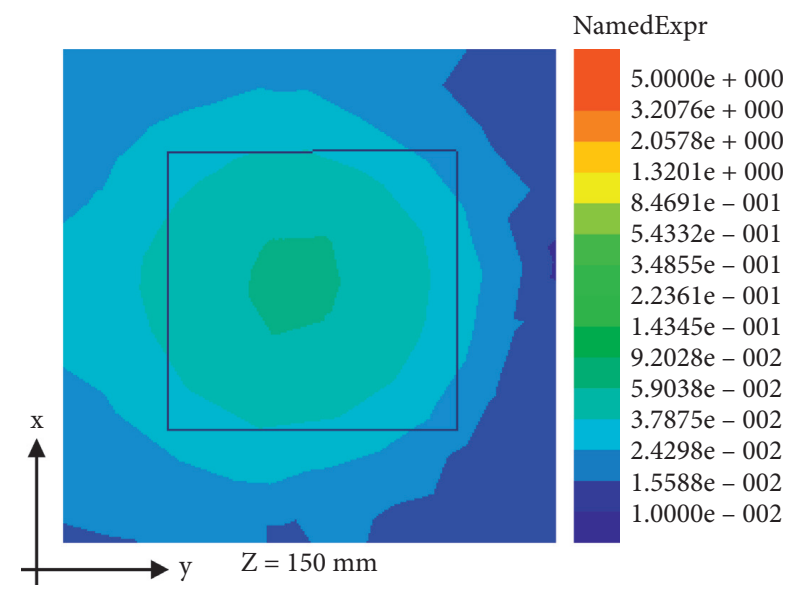

(d)

FIGURE 13: Simulated Ez distributions of the three-branch antenna at different heights when the substrate thickness $h=0.5 \mathrm{~mm}$. (a) $Z=30 \mathrm{~mm}$. (b) $Z=50 \mathrm{~mm}$. (c) $Z=100 \mathrm{~mm}$. (d) $Z=150 \mathrm{~mm}$.

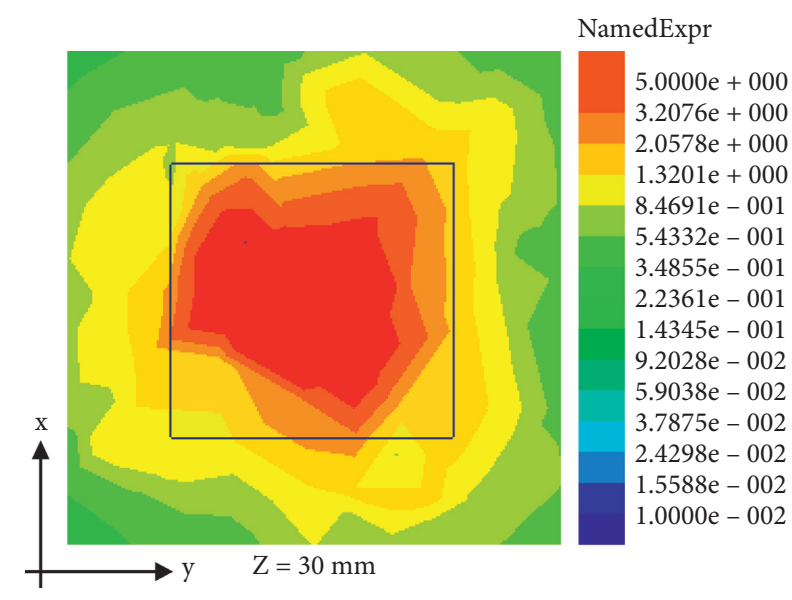

(a)

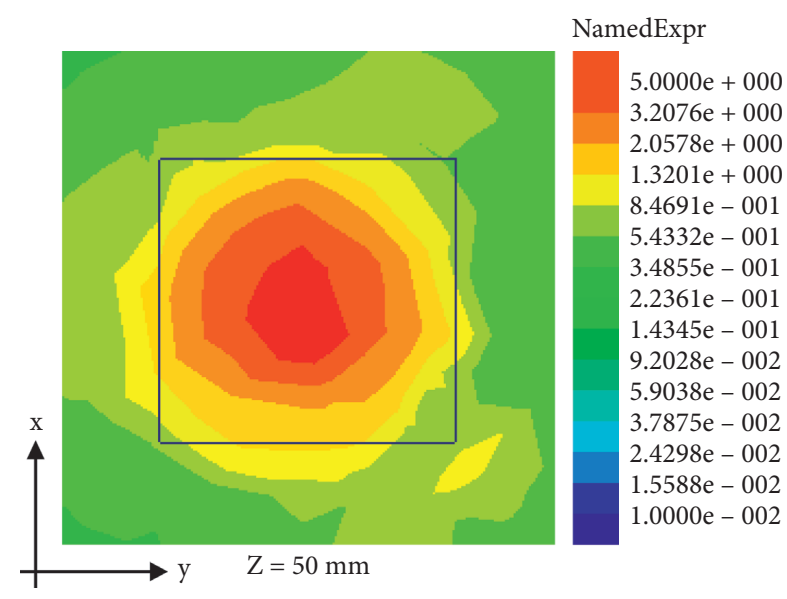

(b)

Figure 14: Continued. 


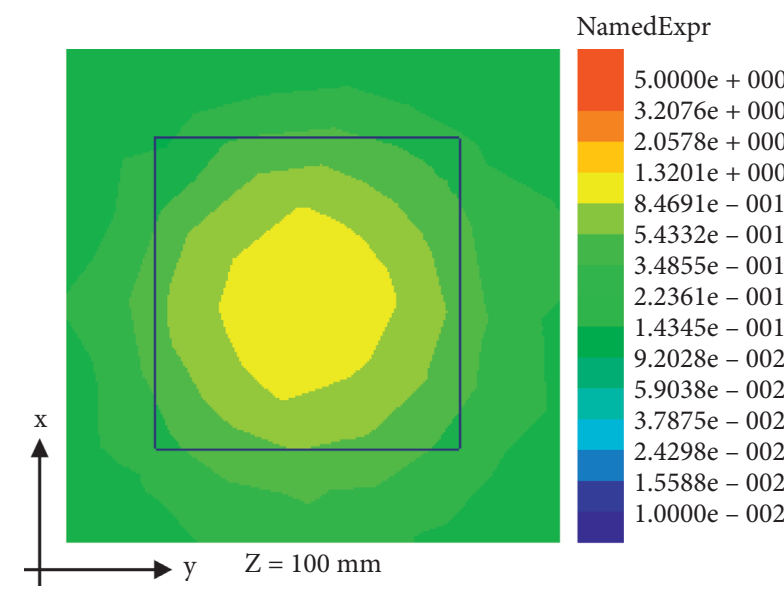

(c)

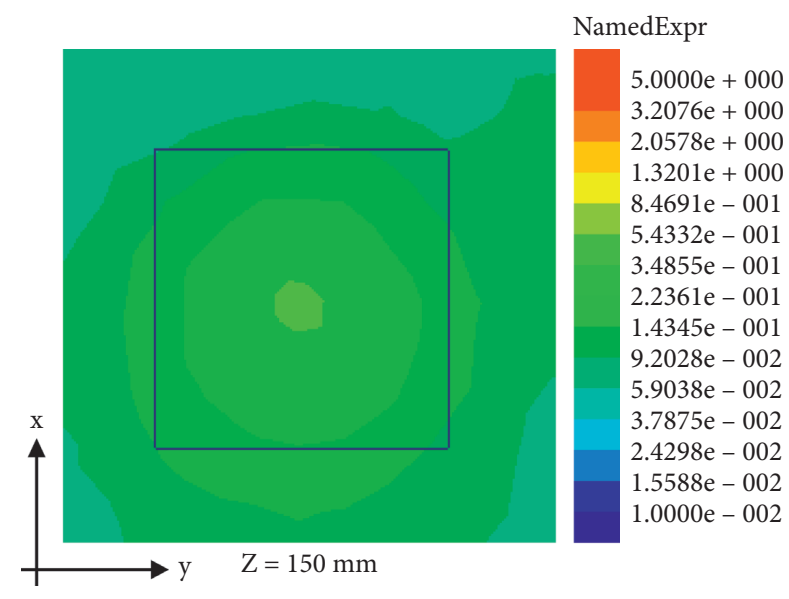

(d)

FIgURE 14: Simulated Ez distributions of the three-branch antenna at different heights when the substrate thickness $h=1.5 \mathrm{~mm}$. (a) $Z=30 \mathrm{~mm}$. (b) $Z=50 \mathrm{~mm}$. (c) $Z=100 \mathrm{~mm}$. (d) $Z=150 \mathrm{~mm}$.

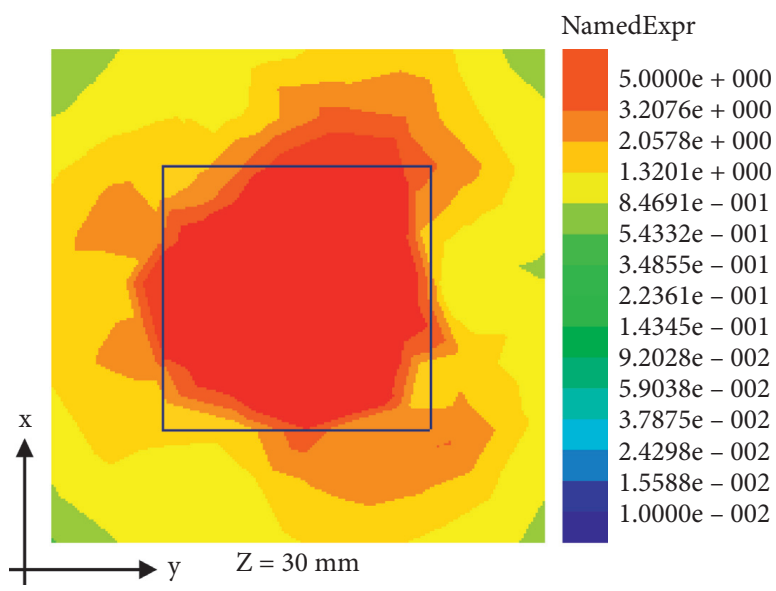

(a)

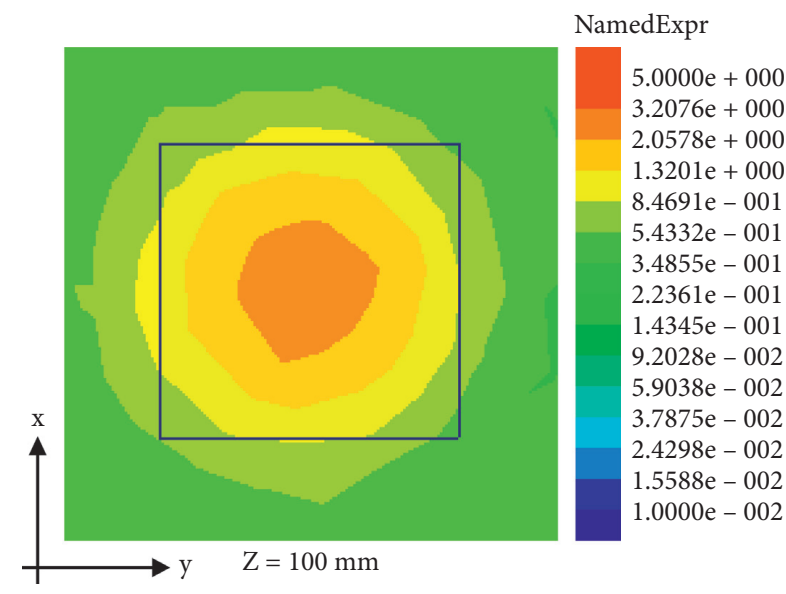

(c)

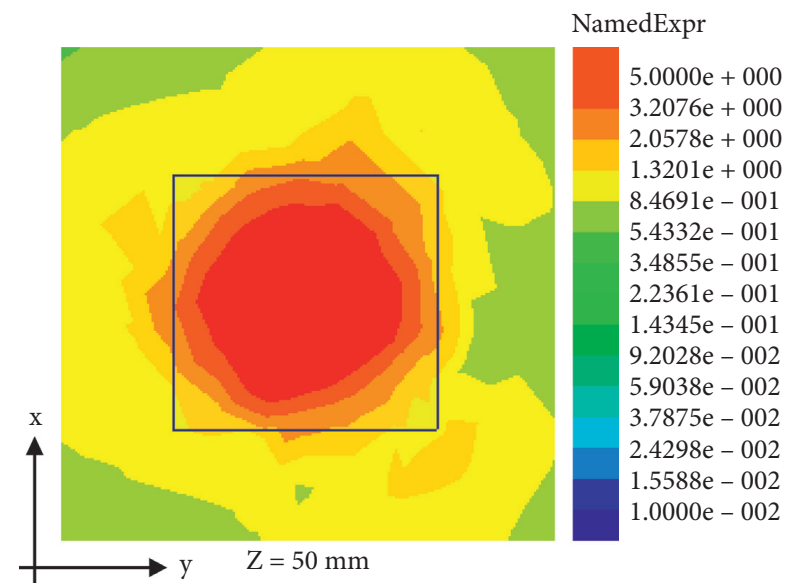

(b)

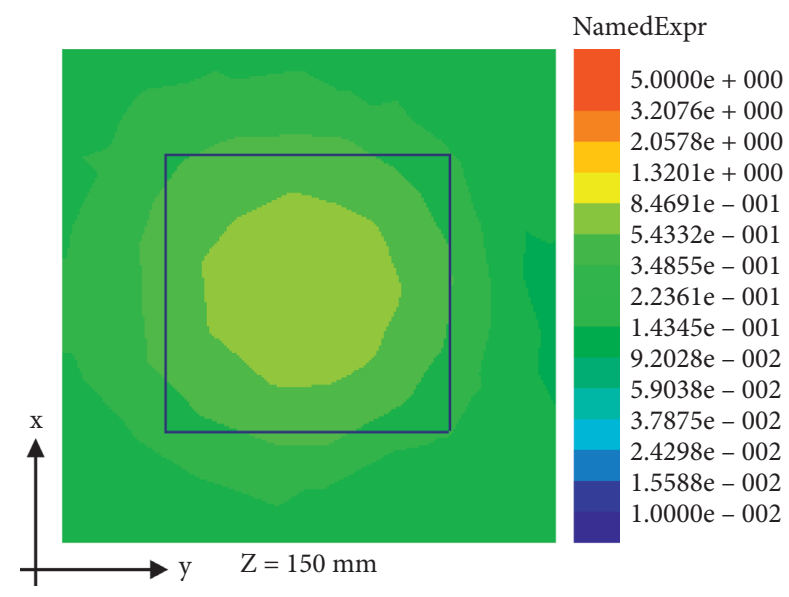

(d)

FIgURE 15: Simulated Ez distributions of the three-branch antenna at different heights when the substrate thickness $h=2.5 \mathrm{~mm}$. (a) $Z=30 \mathrm{~mm}$. (b) $Z=50 \mathrm{~mm}$. (c) $Z=100 \mathrm{~mm}$. (d) $Z=150 \mathrm{~mm}$. 


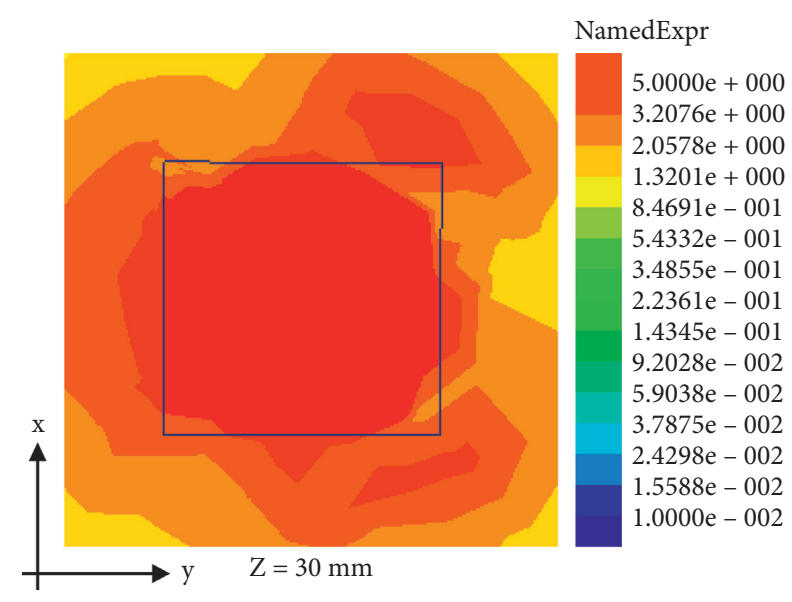

(a)

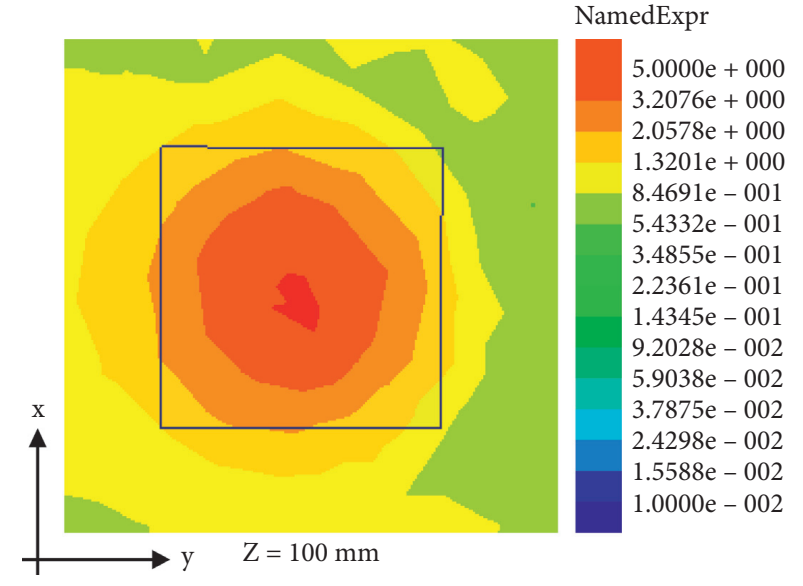

(c)

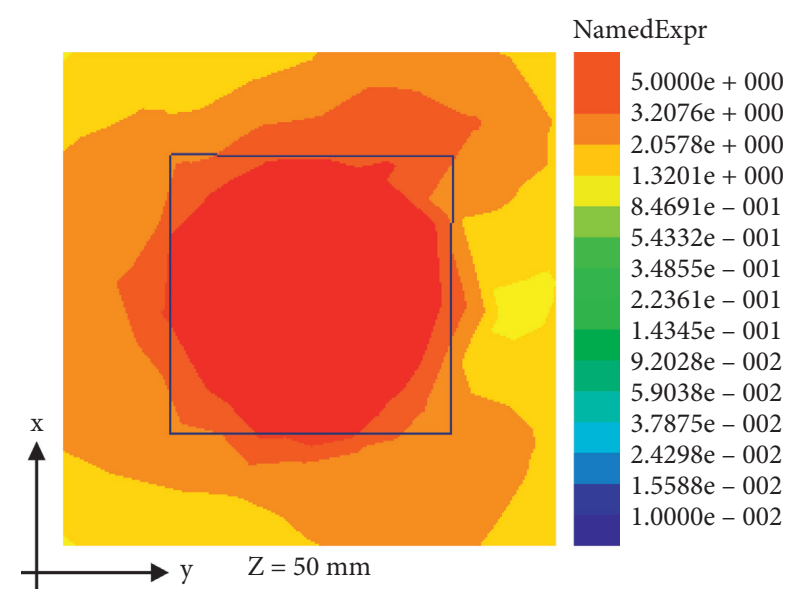

(b)

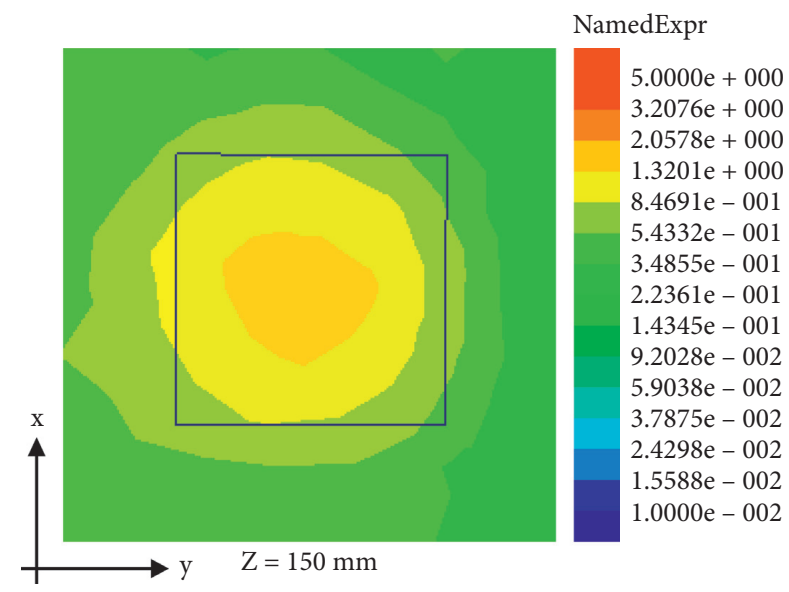

(d)

FIGURE 16: Simulated Ez distributions of the three-branch antenna at different heights when the substrate thickness $h=3.5 \mathrm{~mm}$. (a) $Z=30 \mathrm{~mm}$. (b) $Z=50 \mathrm{~mm}$. (c) $Z=100 \mathrm{~mm}$. (d) $Z=150 \mathrm{~mm}$.

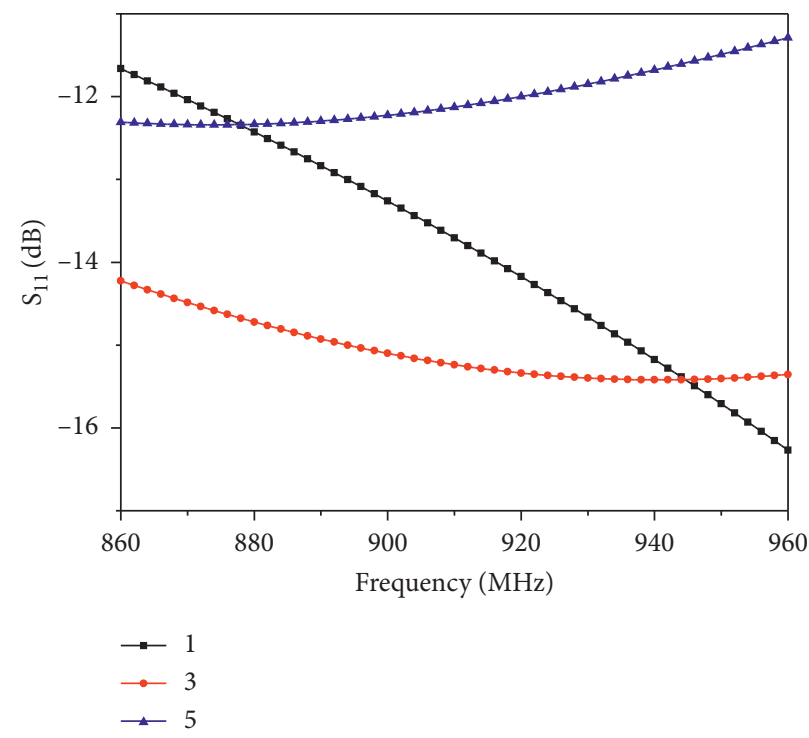

FIGURE 17: Simulated reflection coefficients of the three-branch antenna with different dielectric constant. 

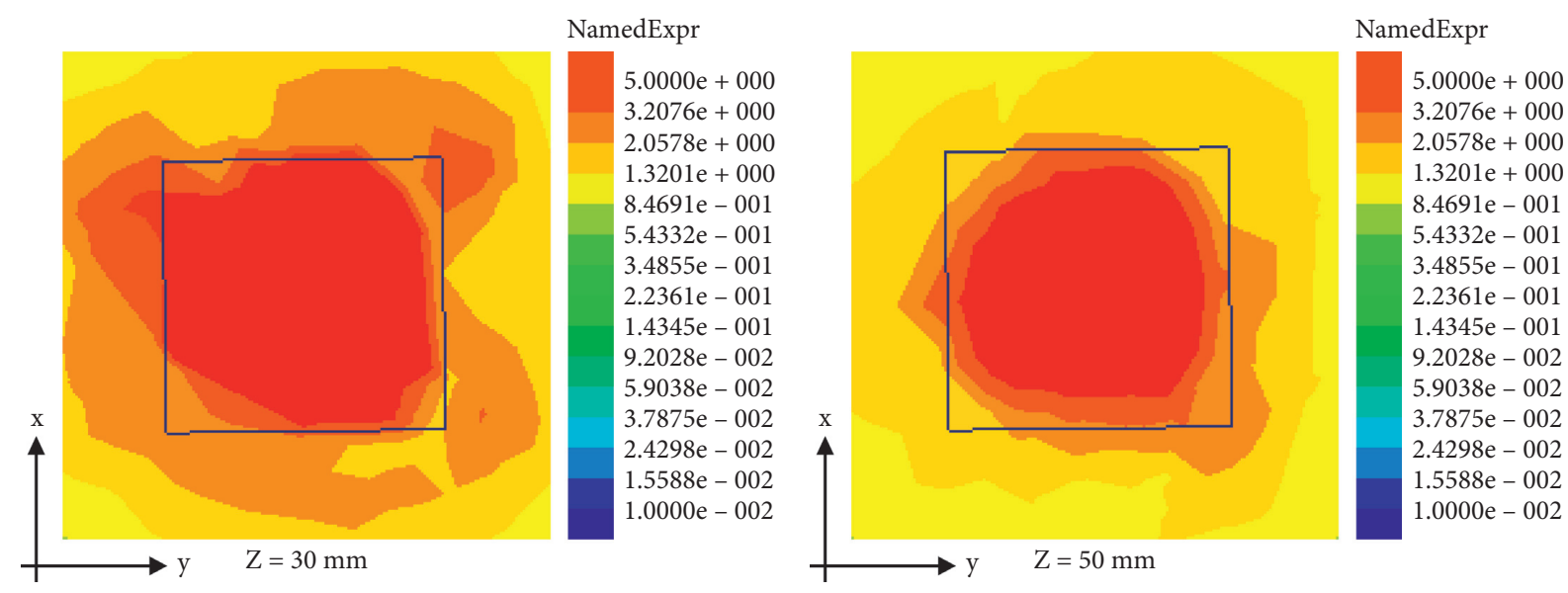

(a)

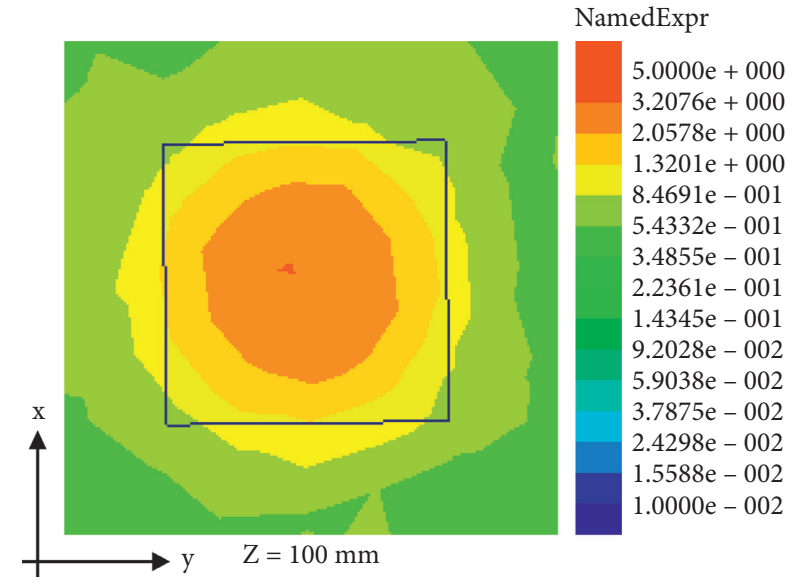

(c)

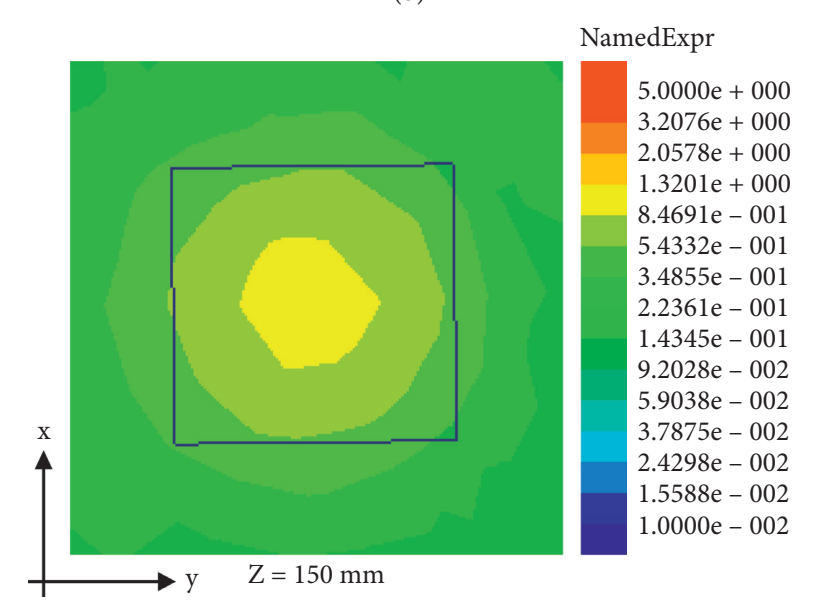

(d)

FIGURE 18: Simulated Ez distributions of the three-branch antenna at different heights when the dielectric constant is 1 . (a) $Z=30 \mathrm{~mm}$. (b) $Z=50 \mathrm{~mm}$. (c) $Z=100 \mathrm{~mm}$. (d) $Z=150 \mathrm{~mm}$.

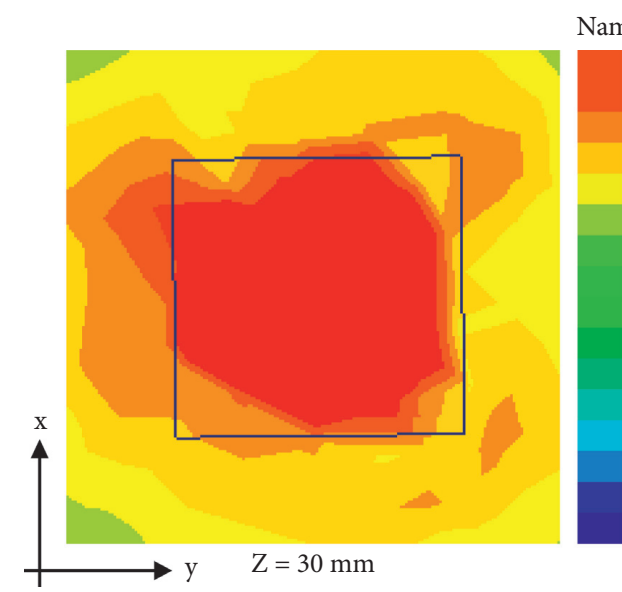

(a)
NamedExpr

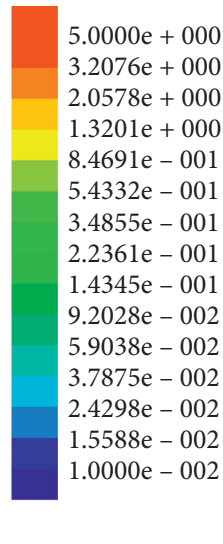

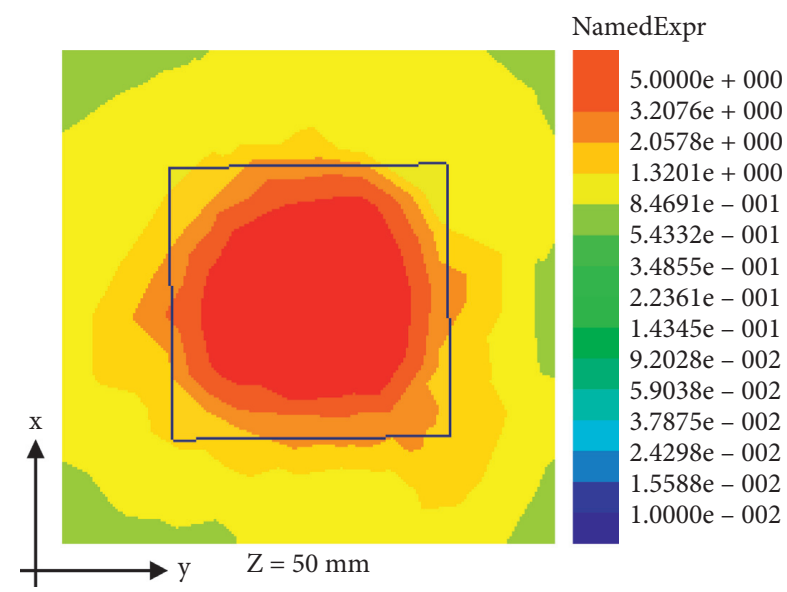

(b)

Figure 19: Continued. 


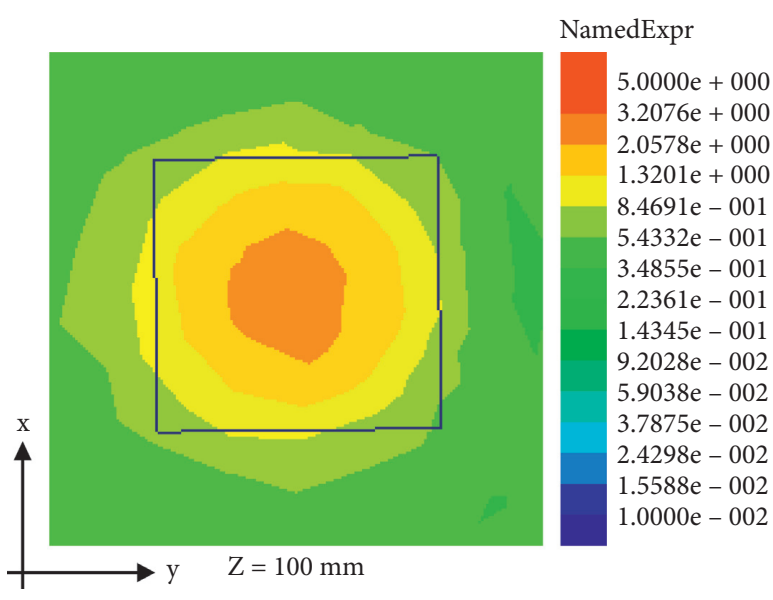

(c)

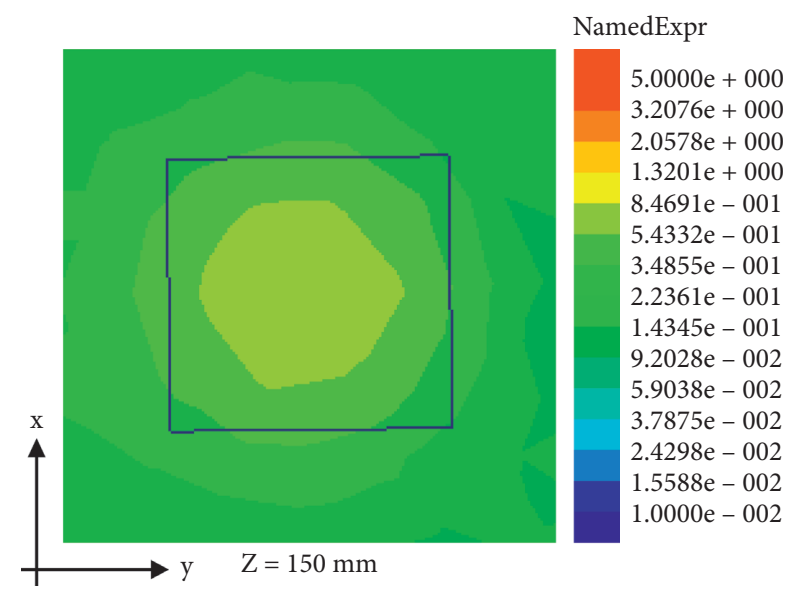

(d)

Figure 19: Simulated Ez distributions of the three-branch antenna at different heights when the dielectric constant is 3 . (a) $Z=30 \mathrm{~mm}$. (b) $Z=50 \mathrm{~mm}$. (c) $Z=100 \mathrm{~mm}$. (d) $Z=150 \mathrm{~mm}$.

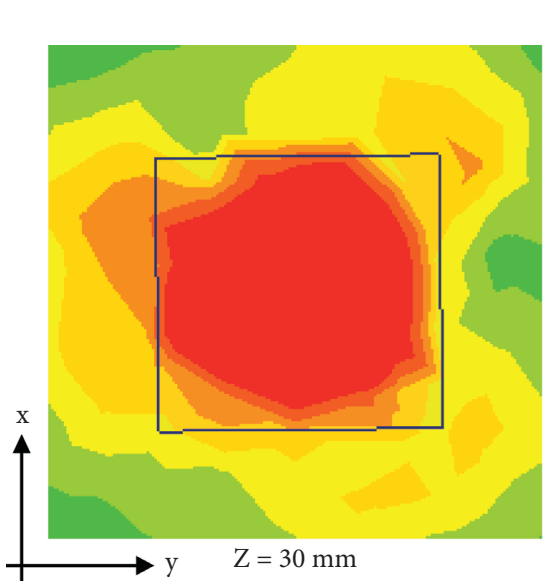

(a)

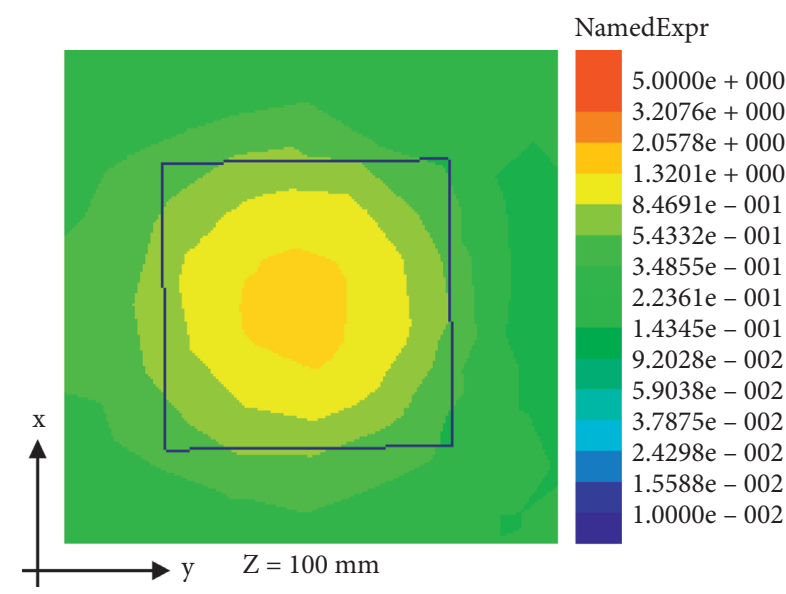

(c)

NamedExpr

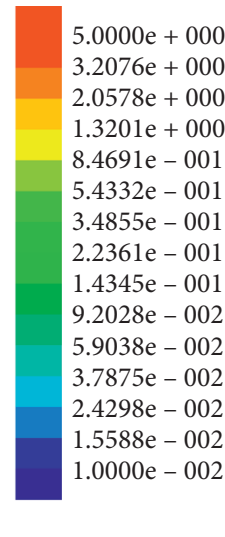

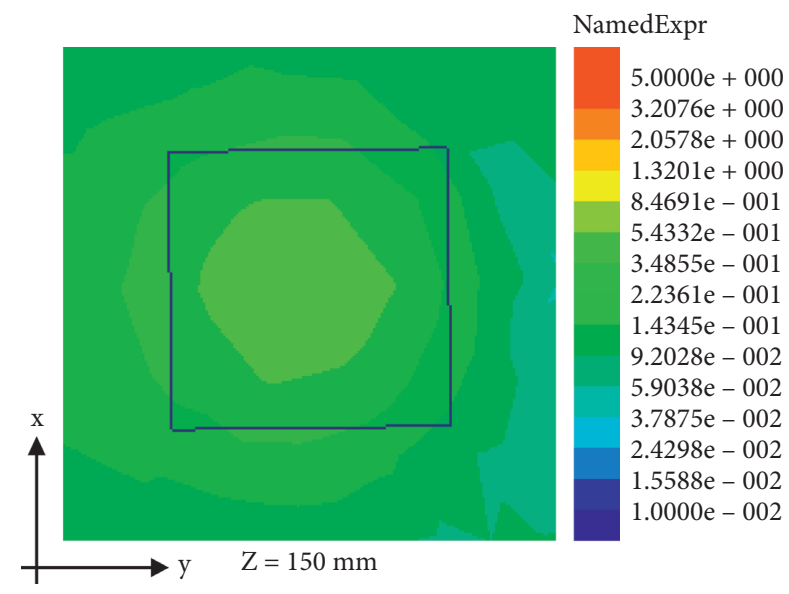

(d)

Figure 20: Simulated Ez distributions of the three-branch antenna at different heights when the dielectric constant is 5 . (a) $Z=30 \mathrm{~mm}$. (b) $Z=50 \mathrm{~mm}$. (c) $Z=100 \mathrm{~mm}$. (d) $Z=150 \mathrm{~mm}$. 


\section{Conclusions}

This article designs two UHF capacitively coupling RFID near-field reader antennas with uniform vertical electric field distribution. Both antennas have broadband characteristics. The vertical electric field components excited by the two antennas are uniformly distributed without zeros, and the tags placed in the vertical direction in the reading area can be read $100 \%$. The two antennas can meet the needs of nearfield applications.

\section{Data Availability}

The dimension parameters of proposed two antennas' data used to support the findings of this study are included in Tables 1 and 2 .

\section{Conflicts of Interest}

The authors declare that there are no conflicts of interest regarding the publication of this paper.

\section{Acknowledgments}

This work was funded by the China Scholarship Council and K. C. Wong Foundation.

\section{References}

[1] J. Landt, “The history of RFID," IEEE Potentials, vol. 24, no. 4, pp. 8-11, 2005.

[2] R. Want, "An introduction to RFID technology," IEEE Pervasive Comput.vol. 5, no. 1, pp. 25-33, 2006.

[3] K. Finkenzeller, RFID Handbook, Wiley, New York, NY, USA, 2nd edition, 2004.

[4] A. Michel and P. Nepa, "UHF-RFID desktop reader antennas: performance analysis in the near-field region," IEEE Antennas \& Wireless Propagation Letters, vol. 15, pp. 1430-1433, 2016.

[5] J. Hong, "A shelf antenna using near-field without dead zones in UHF RFID," in Proceedings of the IEEE International Conference on Industrial Technology, pp. 1-4, Gippsland, Australia, February 2009.

[6] D. M. Dobkin, S. M. Weigand, and N. Iyer, "Segmented magnetic antennas for near- field UHF RFID," Microwave Journal, vol. 50, no. 6, p. 96, 2007.

[7] X. Qing, Z. N. Chen, and C. K. Goh, "UHF near-field RFID reader antenna with capacitive couplers," Electronics Letters, vol. 46, no. 24, pp. 1591-1592, 2010.

[8] Y. S. Ong, X. Qing, C. K. Goh et al., "A Segmented loop antenna for UHF near-field RFID," in Proceedings of the 2010 IEEE Antennas and Propagation Society International Symposium, pp. 1-4, Toronto, Canada, July 2010.

[9] Z. N. Chen, C. K. Goh, and X. Qing, "Loop antenna for UHF near-field RFID reader," in Proceedings of the 4th European Conference of Antenna and Propagation, pp. 1-4, Barcelona, Spain, April 2010.

[10] Y. Zeng, Z. N. Chen, X. Qing, and J.-M. Jin, "Design of a nearfield nonperiodic zero phase shift-line loop antenna with a full dispersion characterization," IEEE Transactions on Antennas and Propagation, vol. 65, no. 5, pp. 2666-2670, 2017.

[11] Y. Zeng, Z. N. Chen, X. Qing, and J.-M. Jin, "A directional, closely spaced zero-phase-shift-line loop array for UHF near- field RFID reader antennas," IEEE Transactions on Antennas and Propagation, vol. 66, no. 10, pp. 5639-5642, 2018.

[12] Y. Yao, Y. Liang, J. Yu, and X. Chen, "A broadband near-field UHF RFID reader antenna with low far-field gain," IEEE Transactions on Antennas and Propagation, vol. 65, no. 9, pp. 4869-4874, 2017.

[13] A. S. Andrenko, "Simultaneous quasi-RHCP and LHCP radiation in the near field of planar RFID antennas," in Proceedings of the 2016 IEEE International Conference on Mathematical Methods in Electromagnetic Theory, Lviv, Ukraine, July 2016.

[14] M.-S. Wang, Y.-X. Guo, and W. Wu, "Planar shared antenna structure for NFC and UHF-RFID reader applications," IEEE Transactions on Antennas and Propagation, vol. 65, no. 10, pp. 5583-5588, 2017.

[15] Y. Yao, Y. Liang, J. Yu, and X. Chen, "Design of a multipolarized RFID reader antenna for UHF near-field applications," IEEE Transactions on Antennas and Propagation, vol. 65, no. 7, pp. 3344-3351, 2017.

[16] Y. Yao, X. Ren, Y. Liang, J. Yu, and X. Chen, "Multipolarized reader antenna with periodic units based on electric field coupling for UHF RFID near-field applications," IEEE Transactions on Antennas and Propagation, vol. 67, no. 8, pp. 5265-5271, 2019. 